\title{
PROBABLE MAXIMUM PRECIPITATION USING STATISTICAL METHOD FOR THE YODO RIVER BASIN
}

\author{
Nor Eliza Alias 1, Pingping LUO 2 and Kaoru TAKARA 3 \\ ${ }^{1}$ Member of JSCE, Doctoral student, Graduate School of Engineering (Dept. of Civil and Earth Resources \\ Engineering), Kyoto University, (Gokasho, Uji City, Kyoto 611-0011, Japan), permanent address: Universiti \\ Teknologi Malaysia, UTM Skudai, 81310, Johor, Malaysia. \\ ${ }^{2}$ Member of JSCE, JSPS Postdoctoral Fellowship, Disaster Prevention Research Institute (DPRI), Kyoto University \\ (Gokasho, Uji City, Kyoto 611-0011, Japan) \\ ${ }^{3}$ Fellow of JSCE, Professor, Disaster Prevention Research Institute (DPRI), Kyoto University, (Gokasho, Uji City, \\ Kyoto 611-0011, Japan)
}

\begin{abstract}
Probable maximum precipitation (PMP) is one of the keys for the designing of probable maximum flood (PMF) and flood disaster management. A basin-scale spatial distribution analysis of the extreme rainfall and PMP in the Yodo river basin are presented. The maximum 24-hour rainfall data from 1881 to 2011 were used. Spatial PMP and its isohyetal lines produced using Hershfield and Spline interpolation method agrees with the historical flood records. Highest PMP is observed around the Hikone and Shimogahara stations (above $900 \mathrm{~mm}$ ), while the least at Yanagase and Torahime (below $500 \mathrm{~mm}$ ). Estimation of the return periods (RPs) using non-linear regression and the generalized extreme value (GEV) distribution for the historical maxima suggests that the GEV overestimates RPs and non-linear regression (NLR) with PMP as upper bound stabilizes the estimates of RP by GEV. Spatial distributions of the 4000 years return periods extreme rainfalls show some similarities with the PMP's distribution.
\end{abstract}

Key Words: Hershfield method, GEV, non-linear regression, extreme rainfall, spatial distribution

\section{INTRODUCTION}

Japan is exposed to various kinds of water-related natural hazards. Typhoons and extreme rainfalls are common in most part of Japan. Probable maximum precipitation (PMP) is one of the keys for the designing of probable maximum flood (PMF) and flood disaster management (hazard map, dam operation, flood control, irrigation, etc.). World Meteorological Organization (WMO, 2009) defines the PMP as "the greatest depth of precipitation for a given duration meteorologically possible over a given size storm area at a particular location at a particular time of the year, with no allowance made for long-term climatic trends"1).

This research conducts extreme rainfall analysis and the PMP estimation for the Yodo river basin. The Yodo river basin extends over six prefectures of Mie, Shiga, Kyoto, Osaka, Hyogo and Nara with an area of $8,240 \mathrm{~km}^{2}$. It includes Lake Biwa and several main rivers (Katsura, Seta-Uji, Kizu and
Yodo rivers) which flow towards the Osaka bay. The population has been increased from the Edo period (1700) to Taisho period (1925), from 2 million to 4.73 million inhabitants. In 2002 the population have reached 14 million $^{2), 3)}$, thus proving the need for such research.

Various hydrological studies have been conducted within the Yodo river basin before. Luo et al. analyzed land use change under the paleoenvironment (1843 to 1976) to explore the effects of human activities on hydrologic response ${ }^{4)}$. Kim et al. developed a numerical model for hydrological and climate change analysis. Combination of the Global Climate Model (GCM) and a hydrological model investigated the possible impacts of climate change from the hydrological viewpoint ${ }^{5)}$. Other researches were more focused towards the water quality analysis and water resources management especially in the Lake Biwa of Yodo river basin. Even though, several statistical researches have been conducted using data from stations within the Yodo 
river basin ${ }^{6,7), 8)}$, extreme rainfall analysis using whole data of the basin has yet to be conducted.

The objective of this paper is to provide statistical analysis of the maximum annual 24-hour rainfall in the Yodo river basin from 1881 to 2011 in terms of the PMP values and to present spatial distribution of the PMP of the basin. The Hershfield statistical method is used for the point PMP estimation, while the PMP spatial distribution is constructed using the spline interpolation and isohyetal method. Return periods of possible extreme rainfalls are also presented and compared with the PMP values.

\section{STUDY SITE AND DATA}

We chose 62 stations for the extreme rainfall analysis and PMP estimation. 31 stations inside the Yodo river basin and 31 stations outside of the basin boundary. The stations outside the Yodo river basin were considered as additional margin for the PMP estimation and spatial distribution analysis for the Yodo river basin. The data were obtained from the Japan Meteorological Agency (JMA). Long historical data (1880 - 2011) belongs to the surface weather observation network, while the rest are from the Automated Meteorological Data Acquisition System (AMeDAS) (1976 - 2011) of JMA. Fig.1 shows the locations of stations selected for the analysis. Distances among each stations are about 20 to $30 \mathrm{~km}$.

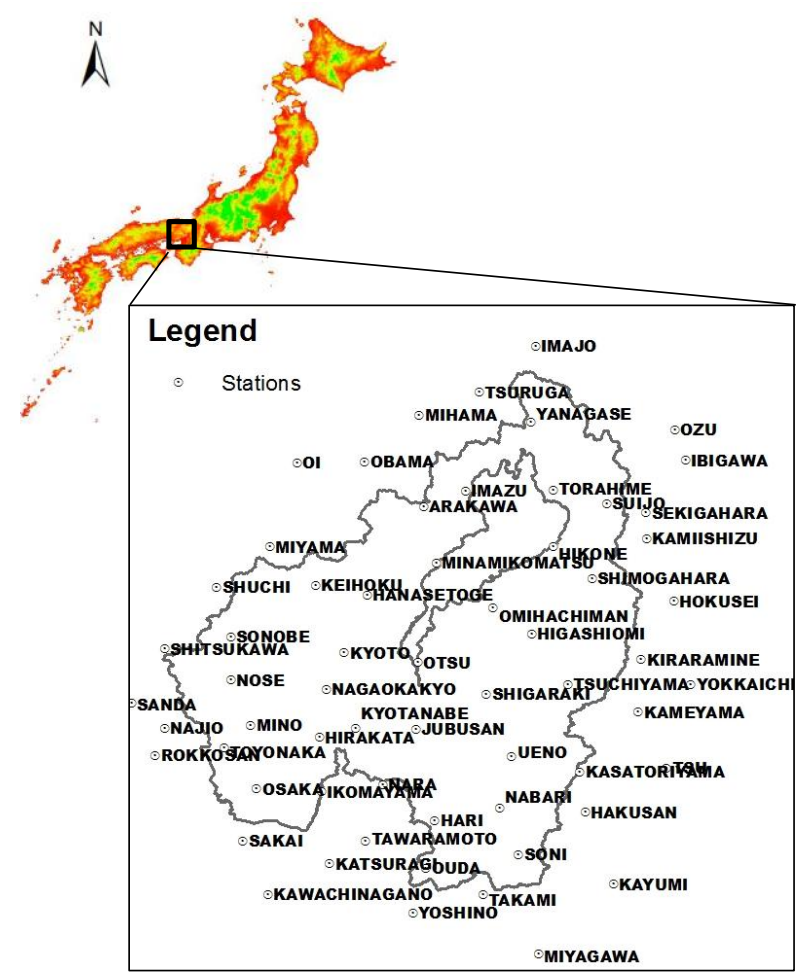

Fig.1 Locations of the Yodo river basin and AMeDAS stations selected for the statistical analysis and PMP estimation.

\section{METHODS}

We use the Hershfield statistical method for estimating the PMP values. The method is being used widely ${ }^{9), 10), 11), 12), 13)}$ and was considered in the manual on estimation of probable maximum precipitation by the World Meteorological Agency ${ }^{1)}$ after it had been modified and developed by Hershfield ${ }^{14), 15)}$. It is also believed to be closely comparable to those obtained by the conventional moisture maximization and storm transposition methods ${ }^{9)}$. The essence of the method is storm transposition, but instead of transposing the specific rainfall amount of one storm, an abstracted statistic $K_{m}$ is transposed ${ }^{1)}$. The Hershfield technique for estimating the PMP value for a station uses the following equations.

$$
\begin{aligned}
& X_{P M P}=X_{n}+S_{n} \times K_{m} \\
& K_{m}=\frac{X_{\max }-X_{n-1}}{S_{n-1}}
\end{aligned}
$$

where, $X_{P M P}$ is the PMP estimates for a station, $X_{n}$ is the mean of the annual extreme series, $S_{n}$ is the standard deviation of the annual extreme series, $K_{m}$ is the frequency factor which depends on the availability of data period, $X_{\max }$ is the highest rainfall value at the station, $X_{n-1}$ is the mean of the annual extreme series without the largest value, and $S_{n-1}$ is the standard deviation of the annual extreme series without the largest value.

First, the parameters $X_{n}, S_{n}$ and $K_{m}$ are calculated. Then, $K_{m}$ values for all stations are plotted against the $X_{n}$ values respectively and an envelope curve is drawn. The new $K_{m}$ value is picked up from the envelope line for each station's $X_{n}$. Finally, the PMP values for each station is calculated using Eq. (1) by replacing $K_{m}$ with the new value.

According to the WMO (2009) ${ }^{1}$ envelopment is a process for selecting the largest value from any set of data. Several researchers applied similar envelopment technique for the Hershfield statistical method $^{13)}{ }^{17)}$. Fig.2 shows the $K_{m}$ plots against $X_{n}$ and its envelope line. We compare two envelops; one considers all the $K_{m}$ values (PMP(1)) while the other exclude the two extreme $K_{m}$ values (PMP(2)).

The two extreme $K_{m}$ values comes from Hikone and Miyagawa. A more smooth an accurate envelope could be obtained if longer records and higher number of extreme rainfalls were recorded. Envelope PMP (1) can be considered as a first order estimation due to the available length of records and data. 


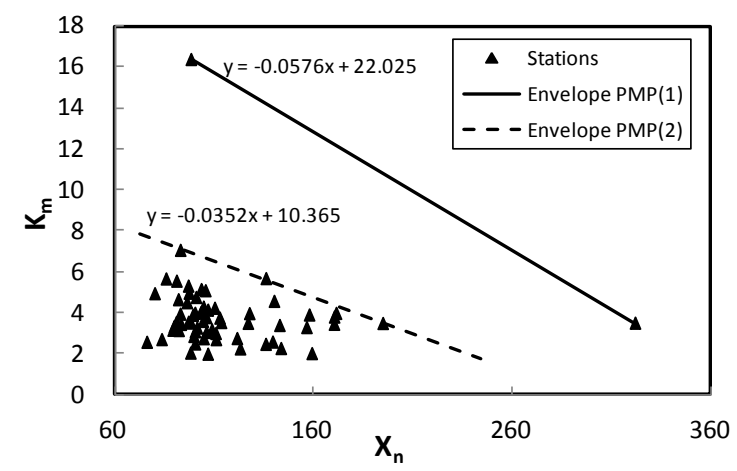

Fig.2 $\mathrm{K}_{\mathrm{m}}$ distribution of the 24-hr PMP for Yodo river basin.

Spline interpolation method in ArcGIS 10 Spatial analyst tool box were used for the interpolation of the PMP spatial distribution. The method was chosen due to its low interpolation error and its approach in preserving the point value whereby the interpolated surface goes through the data points ${ }^{16)}$.

\section{RESULTS AND DISCUSSIONS}

\section{(1) Maximum 24-hour rainfall time series}

Fig.3 illustrates the annual maximum 24-hour rainfall distribution of stations within the Yodo river basin from 1880 to 2011 . The observed data ranges from 29 years to 131 years. The longest observation data were obtained from Kyoto, Osaka and Hikone stations which have 131, 129 and 118 years of observation respectively, while the others have only up to 36 years. This corresponds to the commencing of AMeDAS in 1974. Information of each station's data and the parameters for the PMP estimation are presented in Table 1.

\section{(2) PMP estimates}

Table 1 shows the PMP estimates and its rainfall statistical properties $\left(X_{n}\right.$ and $\left.X_{\max }\right)$ of each station. By excluding the extreme $K_{m}$ values, the PMP estimates $\left(\mathrm{PMP}_{2}\right)$ become very small, justifying the importance to include the extreme values for the PMP estimation. Therefore, values of $P M P_{l}$ were used throughout the study. In addition, Table 1 also shows higher $X_{\max }$ has higher PMP estimates indicating good correspondence between them.

The Hershfield statistical method uses a transposed frequency factor $K_{m}$ for its PMP estimation; which considers the average maximum rainfall, $X_{n}$ of one station instead of just the largest maximum rainfall, $X_{\max }$. Thus, for this case Soni station has the highest estimated PMP value due to its high $X_{n}$ even though Hikone's $X_{\max }$ is much

higher. Hikone station has 118 years data compared to Soni station with 36 years data, resulting into Hikone's $X_{n}$ being much less than Soni's. Therefore, the PMP value in Soni is overestimated due to its less numbers of observations. More accurate PMP estimates could be obtained from longer data records.

Generally, both highest range of PMP value and maximum rainfalls are observed at Soni, Hikone and Shimogahara (PMP values higher than $1000 \mathrm{~mm}$, and Xmax higher than $300 \mathrm{~mm}$ ), followed by Nabari, Ueno, Kasatorayama and Toyonaka (PMP values higher than 800 and Xmax higher than 250 $\mathrm{mm})$.

Table 1 Statistical properties of the annual maximum 24-hour rainfall and PMP values $(\mathrm{mm})$ of the selected 62 stations.

\begin{tabular}{|c|c|c|c|c|}
\hline Stations (Years) & $X_{n(\text { mean })}$ & $X_{\max }$ & $P M P_{I}$ & $\mathrm{PMP}_{2}$ \\
\hline Ueno (74) & 106.53 & 286.7 & 881 & 429 \\
\hline Kasatoriyama (36) & 158.85 & 259 & 846 & 414 \\
\hline Nabari (36) & 103.17 & 295 & 910 & 441 \\
\hline Yanagase (36) & 100.07 & 157 & 444 & 245 \\
\hline Imazu (36) & 91.85 & 164 & 534 & 280 \\
\hline Torahime (33) & 75.79 & 120 & 390 & 213 \\
\hline Arakawa (29) & 110.62 & 223 & 788 & 391 \\
\hline Suijo (33) & 100.03 & 249 & 728 & 364 \\
\hline Minamikomatsu (36) & 110.47 & 188 & 572 & 301 \\
\hline Hikone (118) & 98.00 & 596.9 & 1007 & 482 \\
\hline Omihachiman (36) & 99.40 & 183 & 638 & 326 \\
\hline Shimogahara (32) & 126.72 & 341 & 1060 & 501 \\
\hline Higashiomi (36) & 90.58 & 174 & 560 & 291 \\
\hline Otsu (34) & 106.50 & 158 & 550 & 291 \\
\hline Shigaraki (36) & 100.58 & 235 & 698 & 352 \\
\hline Tsuchiyama (36) & 121.18 & 231 & 794 & 394 \\
\hline Keihoku (36) & 104.40 & 209 & 734 & 368 \\
\hline Hanasetoge (34) & 122.76 & 215 & 758 & 379 \\
\hline Sonobe (36) & 112.46 & 259 & 843 & 413 \\
\hline Kyoto (131) & 105.29 & 288.6 & 738 & 369 \\
\hline Nagaokakyo (36) & 113.19 & 239 & 766 & 382 \\
\hline Kyotanabe (36) & 91.65 & 200 & 595 & 306 \\
\hline Nose (36) & 104.01 & 221 & 725 & 363 \\
\hline Mino (33) & 102.94 & 259 & 749 & 374 \\
\hline Hirakata (36) & 90.56 & 172 & 587 & 302 \\
\hline Toyonaka (36) & 96.65 & 272 & 837 & 410 \\
\hline Osaka (129) & 90.75 & 250.7 & 632 & 322 \\
\hline Ikomayama (36) & 92.65 & 275 & 773 & 382 \\
\hline Hari (36) & 97.01 & 220 & 636 & 325 \\
\hline Soni (36) & 156.21 & 370 & 1140 & 524 \\
\hline Ouda (36) & 96.00 & 235 & 746 & 371 \\
\hline Takami (30) & 170.05 & 449 & 1366 & 598 \\
\hline Yoshino (21) & 105.71 & 226 & 787 & 390 \\
\hline Ozu (27) & 171.09 & 421 & 1159 & 524 \\
\hline Ibigawa (33) & 157.53 & 354 & 963 & 457 \\
\hline Sekigahara (36) & 143.28 & 245 & 817 & 403 \\
\hline Kamiishizu (36) & 139.11 & 290 & 1048 & 494 \\
\hline Hokusei (36) & 139.85 & 310 & 807 & 400 \\
\hline Kiraramine (32) & 170.13 & 394 & 915 & 437 \\
\hline Yokkaichi (46) & 127.41 & 295 & 857 & 419 \\
\hline Kameyama (36) & 135.64 & 242 & 810 & 401 \\
\hline Hakusan (33) & 142.59 & 324 & 1019 & 482 \\
\hline Kayumi (36) & 194.57 & 498 & 1304 & 555 \\
\hline Miyagawa (34) & 321.56 & 764 & 848 & 178 \\
\hline Imajo (36) & 97.78 & 141 & 471 & 255 \\
\hline Tsuruga (111) & 101.04 & 211.2 & 677 & 343 \\
\hline Mihama (36) & 104.28 & 269 & 876 & 427 \\
\hline Oi (16) & 105.75 & 218.5 & 880 & 429 \\
\hline Obama (36) & 99.00 & 232 & 777 & 385 \\
\hline Tsu (111) & 135.73 & 427 & 969 & 463 \\
\hline Miyama (33) & 96.70 & 196 & 649 & 330 \\
\hline Shuchi (29) & 97.83 & 206 & 716 & 359 \\
\hline Jubusan (34) & 92.60 & 204 & 674 & 340 \\
\hline Sakai (36) & 83.26 & 163 & 651 & 328 \\
\hline Kawachinagano (35) & 92.93 & 213 & 693 & 348 \\
\hline Shitsukawa (36) & 108.50 & 232 & 816 & 402 \\
\hline Sanda (36) & 88.83 & 188 & 700 & 351 \\
\hline Najio (30) & 109.93 & 269 & 873 & 426 \\
\hline Rokkosan (30) & 100.10 & 175 & 650 & 331 \\
\hline Nara (59) & 89.47 & 182.3 & 607 & 311 \\
\hline Tawaramoto (36) & 79.75 & 191 & 599 & 305 \\
\hline Katsuragi (31) & 85.47 & 196 & 574 & 295 \\
\hline
\end{tabular}




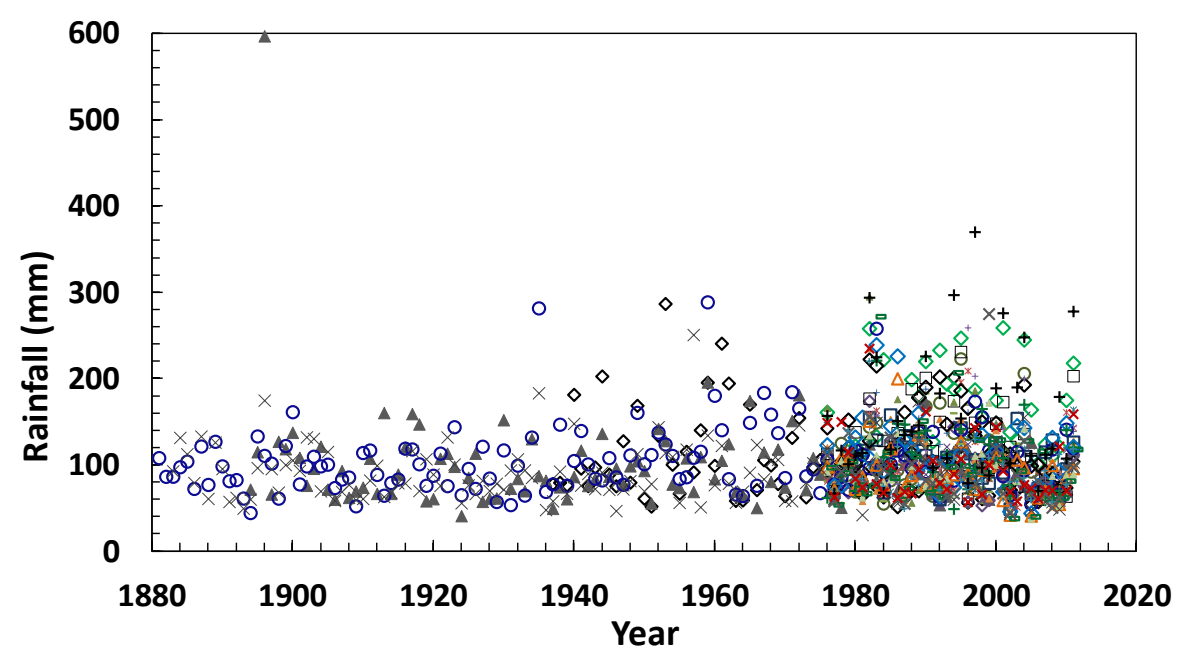

Fig.3 Distribution of the annual maximum 24-hour rainfall observation in the Yodo river basin.

\section{(3) Spatial PMP estimates}

A more detail analysis of the PMP in a river basin could be presented using PMP spatial distribution. The PMP spatial distribution and 40-mm interval isohyetal lines for the Yodo river basin is presented in Fig.4. PMP values at any point in the river basin could be estimated from the isohyetal lines. The isohyetal lines clearly show the range of PMP values. The highest PMP observed is around the Hikone and Shimogahara stations which are from 900 to $1040 \mathrm{~mm}$, while the lowest is at the north side of Lake Biwa around Yanagase and Torahime where the isohyetal lines are less than 500 $\mathrm{mm}$. At the south-east of the basin, areas around Soni, Nabari Ouda and Ueno also show quite high PMP values (800 to $1300 \mathrm{~mm}$ ).

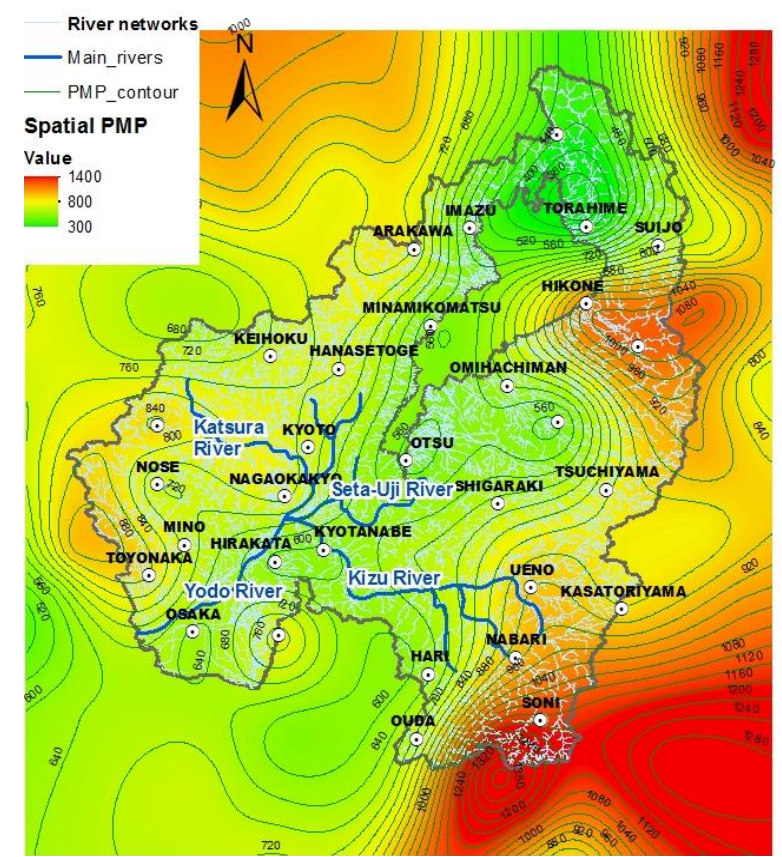

Fig. 4 Yodo river basin main rivers, isohyetal map of the PMP and the PMP spatial distribution.

\section{(4) Comparison of PMP with historical flood events}

Extreme rainfalls have been proven to influence the discharge within the Yodo river basin ${ }^{4)}$, therefore the spatial PMP distribution of the Yodo river basin is compared with previous flood records. Table 2 presents flood disaters in the Yodo river basin according to the main rivers' maximum flow and the Yodo river's maximum water level. During every flood event the Kizu river frequently has the largest maximum flow compared to Katsura and Uji rivers. Generally, this agrees with the estimated spatial PMP distribution in Fig.4 which shows areas around Kizu river having higher PMP range (800 $\mathrm{mm}$ to $1300 \mathrm{~mm}$ ) compared to areas around Katsura and $\mathrm{Uji}$ rivers $(600 \mathrm{~mm}$ to $800 \mathrm{~mm})$.

\section{(5) Return periods of extreme rainfalls estimates}

Fig. 5 shows return periods for the annual maximum 24-hour rainfall for several stations with the highest PMP values within the Yodo River basin. Return periods based on the generalized extreme value distribution (GEV) were plotted and a non-linear regression equation (NLR) for each station were produced. The NLR equation produced is:

$$
Y=\alpha X^{\beta} \quad, 0<Y<P M P
$$

where $Y=$ rainfall, $X=$ return period, $\alpha, \beta=$ constants and a $P M P$ as the upper boundary for $Y$. The parameters $\alpha$ and $\beta$ are estimated by the non-linear regression method using the plots based on the GEV distribution. If we assume the PMP value to be the maximum (upper bounds) of this NLR lines, as an example Soni's PMP $(1140 \mathrm{~mm})$ can be plotted at a 
Table 2 Flood disasters in the Yodo river basin ${ }^{1)}$.

\begin{tabular}{lccccc}
\hline \multirow{4}{*}{ Date } & \multicolumn{4}{c}{ Maximum flow $\left(\mathrm{m}^{3} / \mathrm{sec}\right)$} & $\begin{array}{c}\text { Max. water } \\
\text { level }(\mathrm{m})\end{array}$ \\
\cline { 2 - 6 } & Kizu & Katsura & Uji & Yodo & Yodo \\
& River & River & River & River & River \\
\hline $25 / 09 / 1952$ & 5800 & 2700 & 1780 & 7800 & 6.97 \\
$27 / 09 / 1955$ & 3850 & 810 & 670 & 4610 & 5.49 \\
$27 / 08 / 1957$ & 3650 & 790 & 525 & 4030 & 5.07 \\
$14 / 08 / 1958$ & 3900 & 2500 & 1270 & 6800 & 6.5 \\
$27 / 09 / 1959$ & 6200 & 1700 & 885 & 7200 & 6.69 \\
$30 / 08 / 1960$ & 770 & 2600 & 310 & 3840 & 4.7 \\
$28 / 10 / 1961$ & 5220 & 2100 & 1000 & 7800 & 6.95 \\
$17 / 09 / 1965$ & 5170 & 2500 & 900 & 6870 & 6.75 \\
$17 / 09 / 1972$ & 3250 & 2320 & 810 & 5230 & 4.64 \\
$02 / 08 / 1982$ & 3980 & 1950 & 990 & 6260 & 4.65 \\
\hline
\end{tabular}

point of $(X=7235, Y=1140)$ based on the GEV distribution. Then the optimized NLR line which stabilizes the GEV can be obtained as:

$$
Y=155.55 X^{0.2368}, 0<Y<1140
$$

Table 3 shows the comparison between the return periods (RPs) estimated by using the GEV and NLR. Both GEV and NLR estimated closely the RPs for the maximum rainfall in most of the stations. However, for higher possible extreme rainfalls $(800 \mathrm{~mm}$ and $1000 \mathrm{~mm}$ ) the estimated RPs have bigger differences. GEV overestimates the RPs because GEV's upper bound is infinite. The NLR with upper bound given by PMP stabilizes the RP estimates. In other words, we can avoid (or reduce) overestimation by using NLR.

Fig. 6 shows spatial distribution of 500-, 2000and 4000-year extreme rainfalls obtained by the GEV distribution ((b), (c) and (d), respectively) as well as PMP (a). Soni, Shimogahara, Nabari, Ueno and Hikone have PMP values around $1000 \mathrm{~mm}$. If compared in Fig.6 and Table 3, the PMPs for Soni, Shimogahara and Nabari are close to the extreme rainfall with 4000 years return period estimated by the GEV distribution. However, Ueno and Hikone are closer to an extreme rainfall with much higher return periods estimated by the GEV (near to 18000 years).

Table 3 PMP and estimates of return periods for historical maximum and possible extreme rainfalls by GEV and NLR.

\begin{tabular}{|c|c|c|c|c|c|c|c|}
\hline \multirow{2}{*}{$\begin{array}{c}\text { Stations } \\
\text { (Observed years) }\end{array}$} & \multirow{2}{*}{\multicolumn{2}{|c|}{$\begin{array}{c}P M P \quad X_{\max } \\
(\mathrm{mm})\end{array}$}} & \multicolumn{5}{|c|}{ Return Period (Years) } \\
\hline & & & & $X_{\max }$ & $400 \mathrm{~mm}$ & $800 \mathrm{~mm}$ & $1000 \mathrm{~mm}$ \\
\hline \multirow[t]{2}{*}{ Soni (36) } & 1140 & 370 & $\overline{G E V}$ & 40 & 55 & 1237 & 3722 \\
\hline & & & NLR & 40 & 54 & 1008 & 2586 \\
\hline \multirow[t]{2}{*}{ Shimogahara (32) } & 1060 & 341 & GEV & 61 & 109 & 1636 & 4048 \\
\hline & & & NLR & 58 & 104 & 1284 & 2879 \\
\hline \multirow[t]{2}{*}{ Nabari (36) } & 910 & 295 & GEV & 71 & 194 & 1973 & 4180 \\
\hline & & & NLR & 65 & 174 & 1531 & N/A \\
\hline \multirow[t]{2}{*}{ Ueno (74) } & 881 & 286.7 & GEV & 76 & 302 & 6430 & 17886 \\
\hline & & & NLR & 70 & 273 & 4257 & N/A \\
\hline \multirow[t]{2}{*}{ Hikone (118) } & 1007 & 596.9 & GEV & 2282 & 464 & 7407 & 18247 \\
\hline & & & NLR & 1225 & 410 & 5748 & 13454 \\
\hline
\end{tabular}

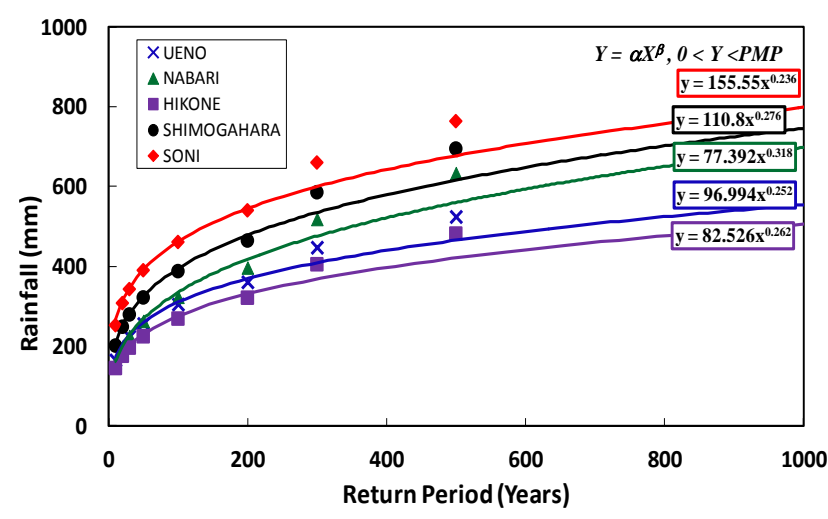

Fig.5 Return periods of stations in the Yodo river basin.

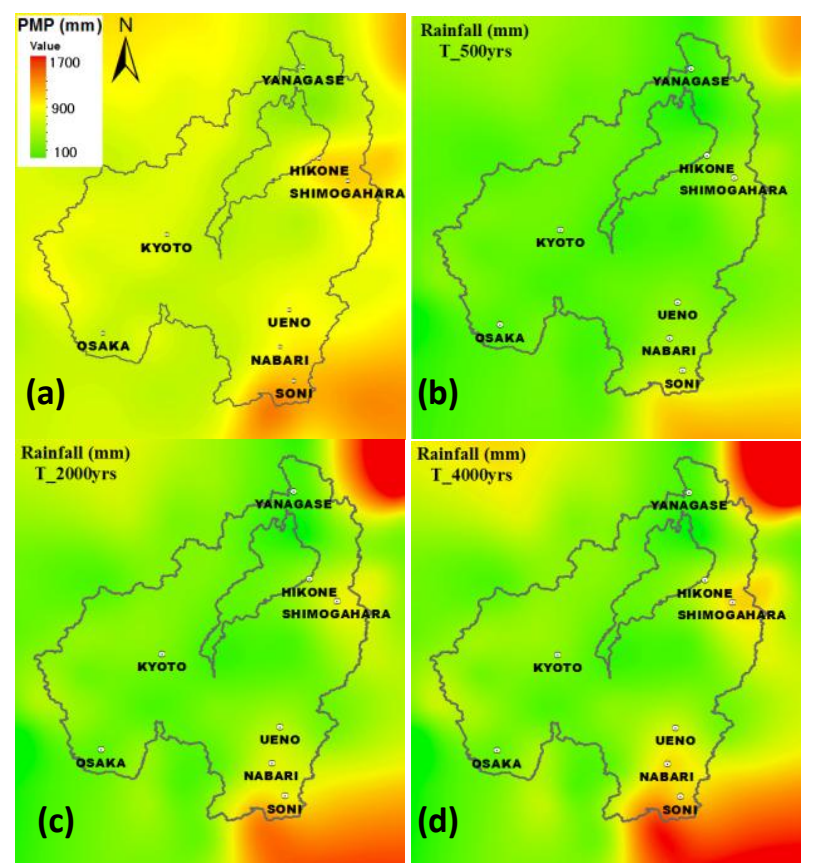

Fig.6 (a) PMP spatial distribution compared with extreme 24-hr rainfall with return periods: (b) 500, (c) 2000 and (d) 4000 years using GEV distribution.

\section{SUMMARY AND CONCLUSIONS}

The PMP estimated using the statistical Hershfield methods corresponds reasonably with the $X_{\max }$ of each stations respectively. Generally the highest ranges of PMP value and maximum rainfalls are observed around Soni, Hikone, Shimogahara, Nabari and Ueno with a PMP value around 1000 $\mathrm{mm}$. However, PMP value in Soni is overestimated due to its few numbers of observations. More accurate PMP estimates could be obtained from longer data records.

From the PMP spatial distribution and isohyetal lines the highest observed PMP is around the Hikone and Shimogahara stations which are from 900 to $1040 \mathrm{~mm}$, while the least is around the Yamagase and Torahime stations where the isohyetal lines are shown to be less than $500 \mathrm{~mm}$. 
The PMP and maximum annual 24-hour rainfall spatial distribution and the PMP isohyetal lines of the Yodo river basin illustrate a good correspondence with the historical flood records. It is estimated that the area around Ueno station, Nabaki station and along the Kizu river has a high PMP value $(800 \mathrm{~mm}$ to $1300 \mathrm{~mm}$ ) compared to areas around Katsura and Uji river $(600 \mathrm{~mm}$ to 800 $\mathrm{mm}$ ) corresponding well to areas with the highest river discharge. Analysis on the GEV and NLR shows the GEV to overestimate the return periods because GEV's upper bound is infinite. The NLR with upper bound given by PMP stabilizes the return period estimates.

Generally, the spatial distribution of the PMP and extreme 24-hour rainfall presented in this paper will be useful as a background material in estimating the area with the most extreme rainfall that is possible to occur in a basin. It can also be used for the planning, designing and management of different type of hydraulic structures and future flood risk management. Comparisons as well as inputs to numerical models can also be conducted. Also, by including PMP analysis together with extreme rainfall return periods optimum decisions can be made easier. Such studies are crucial for basins with high population and exposed to various kinds of water related natural disasters.

ACKNOWLEDGMENTS: This study was supported by the Postdoctoral fellowship of Japan Society for the Promotion of Science (P12055), JSPS KAKENHI Grant Number 24.02055, and the Kyoto University Global COE program on "Sustainability/Survivability Science for a Resilient Society Adaptable to Extreme Weather Conditions". The authors wish to thank the Japan Meteorological Agency (JMA) for providing the data.

\section{REFERENCES}

1) World Meteorological Organization (WMO), Manual for Estimation of Probable Maximum Precipitation, Publication No.1045, World Meteorological Organization, Geneva, 2009.

2) Shiga Prefectural Government, Department of Lake Biwa and Environment, Water Policy Division: Towards Integrated Basin Management in Lake Biwa and Yodo River Basin-Past and Future, presented in the International Forum on ILBM-G Project 090307, 2007.

3) Kinki Regional Development Bureau, Ministry of Land, Infrastructure and Transport: 2002 Lake Biwa and Yodo River, 2002.

4) Luo, P., Takara, K., Apip, He, B., Nover, D. and Yamashiki, Y.: Land use change analysis and paleo-flood in the Kamo river basin, Kyoto, Japan, Journal of Japan Society of Civil Engineers, Ser.B1 (Hydraulic Engineering), Vol. 68, No.4,pp.I_127-I_132, 2012.
5) Kim, S., Tachikawa, Y., Takara, K. and Nakakita, E.: Hydrologic prediction under global warming at Tone and Yodo river basin using the output of Global 20-km mesh GCM, Annuals of Disaster Prevention Research Institute, Kyoto University, No.51 B, pp. 11 -20, 2008.

6) Takara, K. and Tosa, K.: Storm and Flood Frequency Analysis Using PMP/PMF Estimates, in Proceedings of International Symposium on Floods and Droughts, UNESCO-IHP, Nanjing, China, 18-20 October, pp. 7-17, 1999.

7) Takasao, T., Takara, K., and Shimizu, A.: A basic study on frequency analysis of hydrologic data in the Lake Biwa basin, Annuals of Disas. Prev. Res. Inst., Kyoto University, 29 B-2, pp. 157-171 (in Japanese), 1986.

8) Takara, K. and Stedinger, J.R.: Recent Japanese Contributions to Frequency Analysis and Quantile Lower Bound Estimators, Stochastic and Statistical Methods in Hydrology and Environmental Engineering, Vol. 1, pp. 217-234,1994.

9) Deshpande, N. R., Kulkarni, B. D., Verma, A. K. and Mandal, B. N.: Extreme rainfall analysis and estimation of Probable Maximum Precipitation (PMP) by statistical methods over the Indus river basin in India, Journal of Spatial Hydrology, 8(1), pp. 22-35, 2008.

10) Koutsoyiannis, D.: A probabilistic view of Hershfield's method for estimating probable maximum precipitation. Water Resour. Res., 35(4), pp. 1313-1322, 1999.

11) Durbude, D. G.: Estimation of probable maximum precipitation for planning of soil and water conservation structures, Journal of Water Conservation, 7(No.3), pp. 31-35, 2008.

12) Desa M, M. N., Noriah, A. B., \& Rakhecha, P. R.: Probable maximum precipitation for $24 \mathrm{~h}$ duration over southeast Asian monsoon region-Selangor, Malaysia, Atmospheric Research, 58(1), pp. 41-54, 2001.

13) Desa M, M. N., \& Rakhecha, P. R.: Probable maximum precipitation for 24-h duration over an equatorial region: Part 2-Johor, Malaysia, Atmospheric Research, 84(1), pp. 84-90, 2007.

14) Hershfield, D.M.: Rainfall Frequency Atlas of the United States. Technical Paper No. 40, Weather Bureau, United States Department of Commerce, Washington, DC, 1961.

15) Hershfield, D.M.: Estimating the probable maximum precipitation, Journal of Hydraulics Division: Proceedings of the American Society of Civil Engineers, 87: pp. 99-106, 1961.

16) Bloschl, G. and Grayson, R.: Spatial Observation and Interpolation. In R. Grayson \& G. Bloschl (Eds.), Spatial Patterns in Catchment Hydrology: Observations and Modelling, Cambridge University Press, UK, 2000.

17) Metreata, S.: Dynamic - Statistical Model for the Determination of Probable Maximum Flood, presented for BALWOIS 2006, Conference on Water Observation and Information System for Decision Support, presentation no. A_098, 2006.

(Received September 30, 2012) 